\title{
An urgent case for higher resolution digital elevation models in the world's poorest and most vulnerable countries
}

\author{
Alanna L. Simpson ${ }^{1}$, Simone Balog ${ }^{1 *}$, Delwyn K. Moller ${ }^{2}$, Benjamin H. Strauss ${ }^{3}$ and \\ Keiko Saito $^{1}$ \\ ' Global Facility for Disaster Reduction and Recovery, World Bank, Washington, DC, USA, ${ }^{2}$ Remote Sensing Solutions, Inc., \\ Pasadena, CA, USA, ${ }^{3}$ Climate Central, Princeton, NJ, USA
}

Keywords: digital elevation model (DEM), disasters, disaster risk management, disaster risk assessment, climate change, climate change impacts, sea level rise, InSAR

OPEN ACCESS

Edited by:

Paul Bates,

University of Bristol, UK

Reviewed by:

Konstantinos Andreadis,

National Aeronautics and Space Administration Jet Propulsion

Laboratory, USA

${ }^{*}$ Correspondence:

Simone Balog,

sbalog@worldbank.org

Specialty section:

This article was submitted to

Hydrosphere,

a section of the journal

Frontiers in Earth Science

Received: 08 June 2015

Accepted: 13 August 2015

Published: 28 August 2015

Citation:

Simpson AL, Balog S, Moller DK,

Strauss BH and Saito K (2015) An urgent case for higher resolution digital elevation models in the world's

poorest and most vulnerable countries. Front. Earth Sci. 3:50

doi: 10.3389/feart.2015.00050
Natural disasters disproportionately impact the poorest countries; low-income developing countries accounted for 95\% of all disaster fatalities between 1970 and 2008 (Handmer et al., 2012). These impacts are generally expected to worsen as the climate changes and sea levels rise. Fortunately, we have the technology today that enables us to determine the likely deaths, damages, and losses (direct and indirect) that will result from natural hazards and climate change, and to highlight which actions will be most effective in reducing impacts on individuals, communities, and governments. This ability to understand disaster and climate losses before they happen and to provide robust analysis of the costs and benefits of preparedness, reduction, and adaptation is a powerful tool in managing disaster risks and adapting to a changing climate.

One of the most critical datasets in this analytical process is a digital elevation model (DEM) (Global Facility for Disaster Reduction and Recovery, 2014). This dataset determines flow of water during a flood, the coastal inundation extent in a tsunami or storm surge, and the loss of coastal areas as the sea level rises. Until recently, one of the only open datasets in developing countries was the SRTM DEM at 90-m spatial resolution (SRTM90), but recently the US Government released the $30-\mathrm{m}$ resolution version. However, major challenges with the $30-\mathrm{m}$ resolution dataset include its great vertical error (up to $16 \mathrm{~m}$ ) and its measurement of surface elevation-including treetops and building tops-not bare earth, which understates flood risk (Sanders, 2007). In contrast, developed countries increasingly are able to access bare-earth elevation datasets with vertical resolutions and accuracies at decimeter scale (e.g., typically below $0.2 \mathrm{~m}$ for LiDAR).

Without this access to high spatial resolution and higher accuracy DEMs, decision-makers in developing countries are forced to use hazard information for planning and preparedness that is inaccurate. Indeed in many cases the use of hazard information generated on available lowresolution DEMs has been shown to be dangerously misleading. In Indonesia, tsunami models were run on three different DEMs_LiDAR, Airborne InSAR and SRTM90-by Geoscience Australia (Griffin et al., 2012). These results, when compared to actual inundation, showed that the use of LiDAR and InSAR datasets enabled an accurate prediction of the inundation extent. Unfortunately, using the SRTM90 datasets did not predict the inundation extent, and in fact, the tsunami waves did not propagate onshore, potentially creating a false sense of safety in the community. Many other similar analyses exist globally, and indeed preliminary analysis also suggests that SRTM-based estimates of global coastal area populations vulnerable to sea level rise and aggravated flooding may be underestimated by more than two times (Kulp and Strauss, in preparation). 
There is an increasing range of technologies available to overcome this challenge, and the acquisition of high-resolution DEMs in developing countries is increasing ${ }^{1}$. However, this process is resource intensive (time and cost); rarely takes advantage of economies of scale; and requires substantial expertise to procure and manage, expertise that can be rare in many government and bi-lateral aid and development institutions.

Fortunately, there is a group of passionate people from a range of sectors committed to advancing the acquisition of highresolution DEMs in the highly vulnerable coastal and riverine areas of the world's poorest ${ }^{2}$. By mobilizing and pooling funds, significant cost savings can be realized through economies of scale. Moreover, this would enable a massive step forward in the accuracy of climate and disaster data and information across the developing world.

These datasets are very high value, low cost, and urgently needed. For instance, quick estimates suggest that an accurate analysis of coastal inundation in Sub-Saharan Africa based on a DEM developed using the latest single-pass, wide-area coverage InSAR technology could be delivered at a fraction of the cost of using standard LiDAR technology. At a reasonable cost, which has been initially estimated at around US\$5 million, the dataset would meet minimum specifications to conduct coastal inundation analysis of an area of about $600,000 \mathrm{~km}^{2}$ (SubSaharan coastal area): bare earth, minimum vertical accuracy of $<50 \mathrm{~cm}$, horizontal resolution of $30 \mathrm{~m}$, and coverage of the coastal zone up to $10 \mathrm{~m}$ vertical change inland ${ }^{3}$. With this

\footnotetext{
${ }^{1}$ Examples include: Manila, Philippines; Tonga; Solomon Islands; and Vanuatu (funded by Australian Aid); Guyana, Haiti, and Sri Lanka (funded by the World Bank Group).

${ }^{2}$ This commentary has been written as part of work with the Digital Elevation Model Project (DEMP) working group. Any errors are the responsibility of the authors.

${ }^{3}$ This vertical change is based on SRTM estimates.
}

\section{References}

Global Facility for Disaster Reduction and Recovery. (2014). Understanding Risk in an Evolving World: A policy note. Washington, DC: World Bank Group.

Griffin, J. G., Latief, H., Kongko, W., Harig, S., Horspool, N., Hanung, R., et al. (2012). "An evaluation of onshore digital elevation models for tsunami inundation modeling," in American Geophysical Union Fall Meeting Abstracts (San Francisco, CA).

Handmer, J. Y., Honda, Z. W., Kundzewicz, N., Arnell, G., Benito, J., Hatfield, I. F., et al. (2012). "Changes in impacts of climate extremes: human systems and ecosystems," in Managing the Risks of Extreme Events and Disasters to Advance Climate Change Adaptation, eds C. B. Field, V. Barros, T. F. Stocker, D. Qin, D. J. Dokken, K. L. Ebi, et al. (Cambridge, UK; New York, NY: Cambridge University Press), 231-290. A Special Report and other datasets, analyses can be done that would tell us the number of communities, kilometers of road, government assets, etc. that are at risk from sea level rise over the coming decades. Taking this example further, efficiently collecting large-scale data meeting the same specifications above with novel airborne InSAR for all the major riverine basins in Sub-Saharan Africa $(10 \mathrm{~km}$ each side of the river) would cost less than US\$10 million (Personal communication).

The advantage of InSAR technology is large coverage and operation through cloud cover, and its capability can now readily meet the specifications put forth. InSAR mapping technology advances have enabled an improved relative vertical accuracy $(<50 \mathrm{~cm})$, albeit at a modest spatial resolution $(\sim 30$ $\mathrm{m}^{2}$ ), over a significant swath making application of this technology relevant in a practical and economic manner. In flood modeling, it can be argued that improved vertical accuracy is more important than spatial resolution, although there is a point when spatial resolution can become too coarse. Although InSAR will not provide a bare-earth measurement, algorithms for removing trees and buildings from InSAR data for flood applications have been successfully developed and with the high-resolution maps $\left(\mathrm{m}\right.$-scale $\left.{ }^{4}\right)$ will work in most regions, except the most densely vegetated ones. However, standard LiDAR products have higher accuracy and resolution that exceed the requirements of the coastal inundation application.

If we are serious about understanding and quantifying the impacts of climate change and disasters on coastal and riverine communities, then we need to get equally serious about collectively investing in public-good datasets, such as higher resolution digital elevation data, that are instrumental in forwarding this understanding.

${ }^{4}$ Prior to generation of the $30 \mathrm{~m} 2$ bare Earth DEM product.

of Working Groups I and II of the Intergovernmental Panel on Climate Change (IPCC).

Sanders, B. (2007). Evaluation of on-line DEMs for flood inundation modeling. Adv. Water Resour. 30, 1831-1843. doi: 10.1016/j.advwatres.2007.02.005

Conflict of Interest Statement: The authors declare that the research was conducted in the absence of any commercial or financial relationships that could be construed as a potential conflict of interest.

Copyright (C) 2015 Simpson, Balog, Moller, Strauss and Saito. This is an open-access article distributed under the terms of the Creative Commons Attribution License (CC $B Y)$. The use, distribution or reproduction in other forums is permitted, provided the original author(s) or licensor are credited and that the original publication in this journal is cited, in accordance with accepted academic practice. No use, distribution or reproduction is permitted which does not comply with these terms. 